\title{
A Suicide Attempt with a Velo-Dog Pocket Revolver in an Alleged Victim of Carjacking
}

\author{
Carlos Durão ${ }^{1}$ and Ricardo Jorge Dinis-Oliveira ${ }^{2,3,4, *(D)}$
}

Citation: Durão, C.; Dinis-Oliveira, R.J. A Suicide Attempt with a Velo-Dog Pocket Revolver in an Alleged Victim of Carjacking. Forensic Sci. 2022, 2, 107-110. https://doi.org/10.3390/ forensicsci2010008

Academic Editors: Dominic Gascho and Sören Kottner

Received: 29 December 2021

Accepted: 30 January 2022

Published: 2 February 2022

Publisher's Note: MDPI stays neutral with regard to jurisdictional claims in published maps and institutional affiliations.

Copyright: (C) 2022 by the authors. Licensee MDPI, Basel, Switzerland. This article is an open access article distributed under the terms and conditions of the Creative Commons Attribution (CC BY) license (https:// creativecommons.org/licenses/by/ $4.0 /)$.
1 Hospital Vila Franca de Xira, 2600009 Vila Franca de Xira, Portugal; carlos.durao@hvfx.min-saude.pt

2 TOXRUN-Toxicology Research Unit, University Institute of Health Sciences, Advanced Polytechnic and University Cooperative (CESPU), CRL, 4585116 Gandra, Portugal

3 Department of Public Health and Forensic Sciences and Medical Education, Faculty of Medicine, University'of Porto, 4200319 Porto, Portugal

4 UCIBIO-REQUIMTE, Laboratory of Toxicology, Department of Biological Sciences, Faculty of Pharmacy, University of Porto, 4050313 Porto, Portugal

* Correspondence: ricardo.dinis@iucs.cespu.pt

\begin{abstract}
In hospital emergencies, we can have the most picturesque and impressive cases, from the simplest to the most complex. Violence cases are not rare, and among these are the injuries caused by firearms, which may vary in severity depending on the affected region and the energy of the projectile. Head injuries are generally very serious, and it is rare the individuals survival without sequelae. This work reports a 38-year-old man who was admitted to the emergency room alone in the morning, walking, lucid, and oriented, mentioning that the night before he was in the car and that he had been shot in the head in an attempt at carjacking. On examination, he had only one entry wound in the right temporal region, and the history revealed a suicide attempt with a very rare firearm: a Velo-Dog. We hypothesized that the low-density energy of this revolver, which historically used to be carried by cyclists as a defense against dog attacks, may partially explains the non-skull penetration.
\end{abstract}

Keywords: Velo-Dog; suicide attempt; survival; crime scene; fake report

\section{Introduction}

While riding a bicycle, especially in the era before regulation was applied to pets and working animals, many cyclists were chased by dogs. This phenomenon led to the invention and popularity of a unique series of revolvers (i.e., the Velo-Dog), one of the smallest revolvers ever placed into production. The Velo-Dog (also known as a "Revolver de Poche") was a pocket revolver originally created in France by René Galand, son of CharlesFrançois Galand, in 1894 to be carried cyclists as a defense against dog attacks [1,2]. The name is composed of "velocipede" and "dog". The available revolvers vary considerably in appearance, but all have certain common features: short barrels, small calibers (e.g., 0.22 or 0.25$)$, a shrouded hammer, and lack of a trigger guard [1,2]. The original revolver used a 5.75-mm (i.e., 0.22-caliber) Velo-Dog cartridge, which is still made by Fiocchi ${ }^{\circledR}$ (Lecco, Italy).

This work reports on a very unusual case of a 38-year-old man who is admitted to the emergency room, mentioning that the night before he was in the car and that he had been shot in the head in an attempt at carjacking. The history revealed a suicide attempt with an antique Velo-Dog firearm.

\section{Case Report}

A 38-year-old man entered an emergency room on his own feet, lucid and oriented, saying that the night before he was in the car and that he had been shot in the head in an attempted carjacking $4 \mathrm{~h}$ before. On examination, he presented only one entry wound in the right temporal region (Figure 1). The observation of the entrance orifice revealed a regular, oval-shaped wound with inverted edges, an excoriated and echimotic area with 
gunpowder tattooing (i.e., a dirty ring), and a circular black zone of soot typical of shots with a barrel slightly in contact to allow some escape of GSR elements around the hole, but without any tattoo zone.

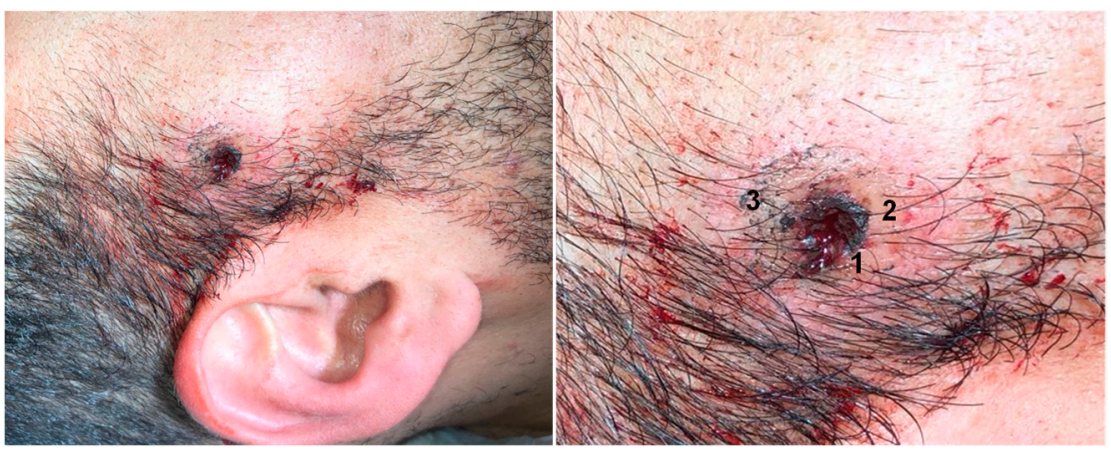

Figure 1. External examination of the victim at the emergency room approximately $4 \mathrm{~h}$ after shot revealed an entrance hole of the projectile in the skull in the right temporal bone with excoriation and wound edge (1), burning zone (2), and soot zone with gunpowder residue deposited around the wounds (3).

The X-ray (Figure 2a,b) and computerized tomography scan (Figure 2c,d) evidenced a projectile lodged between the scalp and the skull, suggesting a low-density projectile energy to penetrate the skull. Based on these findings, it was clear that the story reported by the victim could not be true, since a shot fired from outside the car (within the range of $1 \mathrm{~m}$ ) with the open window in his story would not produce the black soot.

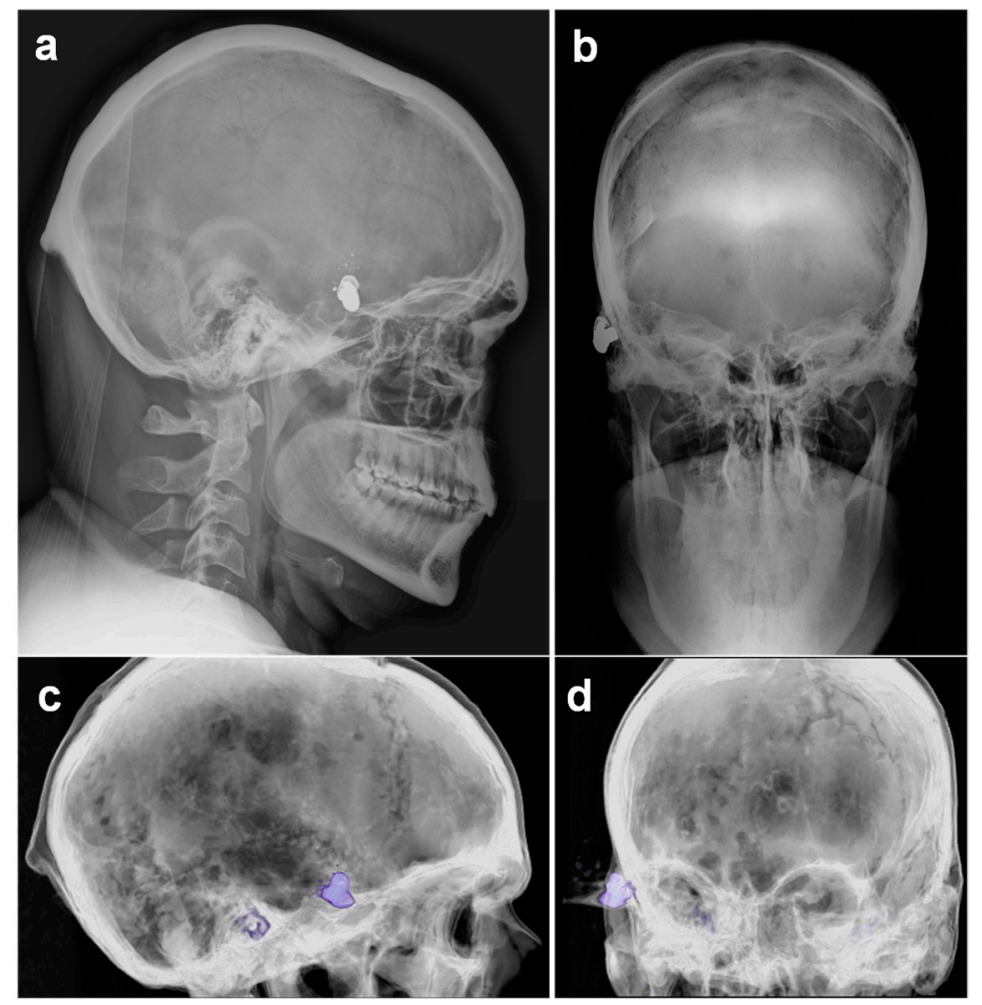

Figure 2. Face (a) and anteroposterior X-ray (b) and respective computerized tomography scans (c,d) of the skull, demonstrating the extracranial location and the deformed lead projectile at the right temporal region.

The support of the judicial police was then requested to clarify the case, and a $6.35 \times 16$ SR mm Velo-Dog revolver was found at the victim's home (Figure 3). The Velo- 
Dog revolver was inherited from a relative, and it is now obsolete. Once faced with these findings, the victim ended up confessing that he fabricated the story of aggression, admitting that he suffered from depression that motivated him to attempt suicide at home. Previous clinical records were not available. The patient fully recovered without major sequels.
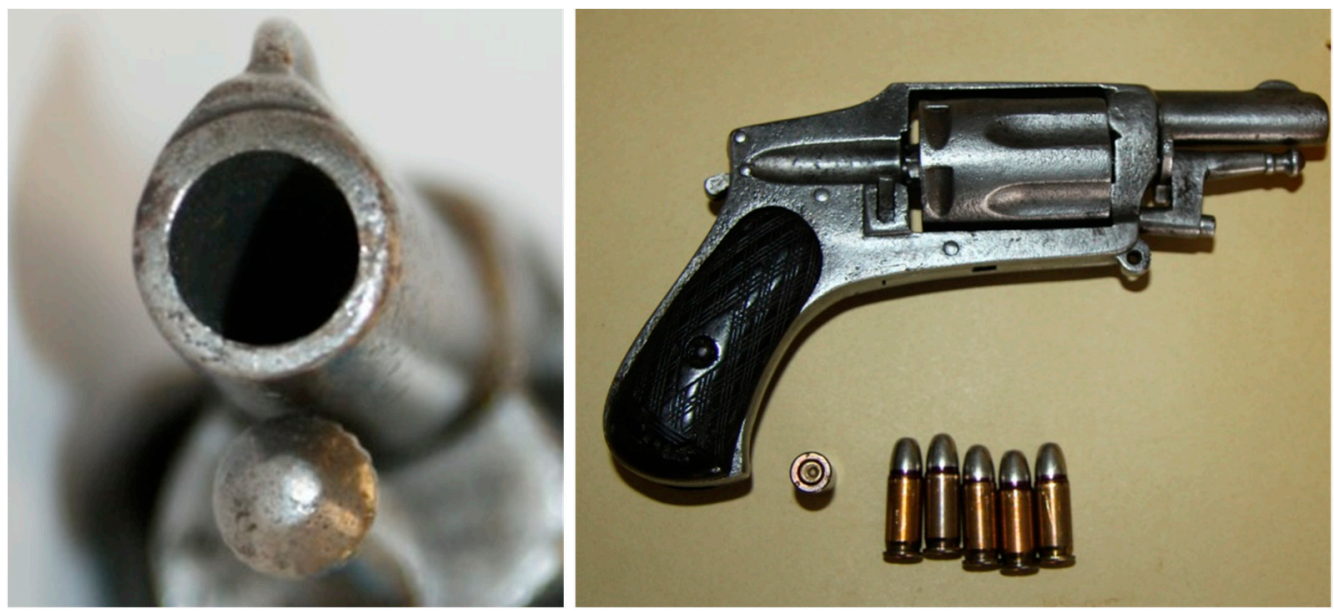

Figure 3. A $6.35 \times 16$ SR mm caliber Velo-Dog revolver found at victim's home with clear correspondence with the gun barrel.

\section{Discussion}

Gunshot wounds to the head are reported means of suicide encountered in the forensic autopsy practice, especially in men, while women more likely to choose overdosing [3-7]. In particular, Velo-Dog revolvers possess a very low-density energy compared with typical handguns, and as evidenced in our case, even close-contact injuries will probably be nonfatal. An essential task of the forensic expert is the reconstruction of events leading to injuries or death, since they can provide valuable information regarding the manner or the cause of production, such as self-inflicted versus inflicted by someone else and as a result of a suicide attempt, accident, or homicide [8]. Close-range or contact injuries from handguns are more often encountered in civilian life, especially in western Europe, and they are thus of particular interest to forensic experts. In the present case, the size, shape of the injury, and abrasions on the right temporoparietal region were interpreted as an entrance wound inflicted by the Velo-Dog. Moreover, the soot depositions around the wound margins were also suggestive of close-range gunshot wounds. Compared with a previous reported case, this was a non-fatal single shot [9]. In that case, the authors observed that the first shot only injured the surface of the outer table of the skull without penetrating the cranial cavity and therefore did not damage the brain or cause any loss of consciousness. In our case, a justification for the failure to penetrate the skull could be explained by the relatively low-density energy of the projectiles used with Velo-Dog revolvers and perhaps due to the application of a single shot. Nevertheless, penetration of the temporal bone at a short distance usually requires lower-density energy $\left(\mathrm{J} / \mathrm{mm}^{2}\right.$; calculated by dividing the kinetic energy of the projectile by the projectile's cross-sectional area) compared with what is expected for this firearm $[10,11]$. Therefore, further reasons could be highlighted. When the firearm was examined, the interior of the barrel was heavily contaminated with soot, suggesting that ammunition combustion had been defective, further reducing the energy of the projectile. An important limitation needs to be mentioned, namely, further information regarding the ammunition and firearm used would be interesting to understand the wounding dynamics, but unfortunately, such data were not available.

This case report illustrates a very unusual suicide attempt with a Velo-Dog pocket revolver and highlights the importance of terminal ballistics in the forensic medical approach. 


\section{Impact Statement}

This case report illustrates a very unusual suicide attempt with an antique VeloDog pocket revolver and highlights the importance of terminal ballistics in the forensic medical expertise.

Author Contributions: Conceptualization, design, formal analysis, and writing of original draft were performed by C.D. and R.J.D.-O. All authors have read and agreed to the published version of the manuscript.

Funding: The authors have no relevant affiliations or financial involvement with any organization or entity with a financial interest in or financial conflict with the subject matter or materials discussed in the manuscript. The potential conflicts include employment, consultancies, honoraria, stock ownership or options, expert testimony, grants or patents received or pending, and royalties.

Institutional Review Board Statement: Not applicable.

Informed Consent Statement: Informed written or oral consent were not required in this case since victim identification was completely avoided. Tattoos and other identifiable items were removed from photos and from the case report description.

Data Availability Statement: Data in the article are in accordance with the consent statement.

Conflicts of Interest: The authors have no conflict of interest to declare. No writing assistance was obtained in the production of this manuscript.

\section{References}

1. Friedman, J.X. Velodogs. 2021. Available online: http://www.velodogs.com/ (accessed on 27 December 2021).

2. $\quad$ Barnes, F.C.; Woodard, W.T. Cartridges of the World: A Complete and Illustrated Reference for over 1500 Cartridges, 16th ed.; Gun Digest Media: Iola, WI, USA, 2019.

3. Junuzovic, M.; Rietz, A.; Jakobsson, U.; Midlöv, P.; Eriksson, A. Firearm deaths in Sweden. Eur. J. Public Health 2019, 29 , 351-358. [CrossRef] [PubMed]

4. Balci, Y.; Canogullari, G.; Ulupinar, E. Characterization of the gunshot suicides. J. Forensic Leg Med. 2007, 14, 203-208. [CrossRef] [PubMed]

5. Thomsen, A.H.; Leth, P.M.; Hougen, H.P.; Villesen, P. Gunshot homicides in Denmark 199-2016. Int. J. Legal Med. 2021, 135, 1507-1514. [CrossRef] [PubMed]

6. Gentile, G.; Galante, N.; Tambuzzi, S.; Zoja, R. A forensic analysis on 53 cases of complex suicides and one complicated assessed at the Bureau of Legal Medicine of Milan (Italy). Forensic Sci. Int. 2021, 319, 110662. [CrossRef] [PubMed]

7. Bready, J.C.; Bready, R.J.; Chute, D.J. A Ten-year Study of Suicides from a Rural/Suburban County. J. Forensic Sci. 2017, 62, 911-914. [CrossRef] [PubMed]

8. Oehmichen, M.; Meissner, C.; König, H.G.; Gehl, H.B. Gunshot injuries to the head and brain caused by low-velocity handguns and rifles: A review. Forensic Sci. Int. 2004, 146, 111-120. [CrossRef]

9. Hayashi, T.; Gapert, R.; Tsoko, M.; Hartwig, S. Suicide with two shots to the head using a rare 'Velo-Dog' pocket revolver. Forensic Sci. Med. Pathol. 2013, 9, 265-269. [CrossRef] [PubMed]

10. Kneubuehl, B.P.; Coupland, R.M.; Rothschild, M.A.; Thali, M.J. Wound ballistics and forensic medicine. In Wound Ballistics: Basics and Applications; Coupland, R.M., Rothschild, M.A., Thali, M.J., Kneubuehl, B.P., Eds.; Springer: Berlin/Heidelberg, Germany, 2011; pp. 253-303. [CrossRef]

11. Caister, A.J.; Carr, D.J.; Campbell, P.D.; Brock, F.; Breeze, J. The ballistic performance of bone when impacted by fragments. Int. J. Legal Med. 2020, 134, 1387-1393. [CrossRef] [PubMed] 